\title{
Bocio y tiroiditis linfocitaria crónica
}

\author{
M.C. Martha Eggers M. ${ }^{1}$; M.C. Amanda Cortínez R. ${ }^{\text {; }}$ M.C. Francisco Beas F. ${ }^{1}$; M.C. Cecilia Henríquez del V. ${ }^{1}$; \\ Germán Iñiguez V. ${ }^{1}$; Cristina Jara A. ${ }^{1}$
}

Goiter and chronic lymphocitic thyroiditis

Sixty patients with goiter, aged 3 to 16 years, 58 girls, were studied for evidence of chronic lymphocytic thyroiditis (CLT). Thirtyeight patients, $63 \%$, presented two or more diagnostic elements of TLC. according to Fishet's criteria, with a high frequency of thyroid function involvement (47.4\% had hypothyroidism and $18.4 \%$ had hyperthyroidism). The rest of the patients with diffuse goiter (37\%) did nol meet Fisher's criteria, they were mostly euthyroidal $(95 \%)$ and they were dessignated "non thyrojditis goiter". All patients with probable CLT had positive antimicrosomal antibodies at relatively high titer $(>1 \times 600$ in $71 \%$ of the cases) and $32 \%$ of them had both antimicrosomal and antithyroglobulin antibodies. In the "non thyroiditis goiter" group we found $28 \%$ of children with positive antimicrosomal antibodies at low titers $(1 \times 100$ and $1 \times 400$, respectively). In a control group of 28 children of similar ages, without endocrine diseases neither familiar history of thyroid diseases only 3 (11\%) cases showed positive an timictosomal antibodies, always at low serum titers.

(Key wonds: goiter, lymphocitic thyroiditis, djagnosis, circulating antibodies, antimicrosomal antibodies, antithyroglobulin antibodies.)

E] bocio es la afección tiroidea de mayor consulta en niños y adolescentes. Su aparición puede ser el resultado de múltiples factores: estimulación de la glándula tiroidea por aumento de la hormona tirotrófica (TSH) secundaria a dishormonogénesis; anticuerpos estimulantes del tiroides, como sucede en la enfermedad de Graves; infiltración del tiroides por quistes, tumores benignos 0 malignos $u$ otras enfermedades 0 inflamación de la glándula tiroides de etiologia autoinmune, infecciosa, viral bacteriana o traumática. En el desarrollo del bocio puede estar comprometido más de un mecanismo. Así, por ejemplo, en enfermedades tiroideas autoinmunes, como la tiroiditis linfocitaria crónica (TLC), por lo general la glandula es infiltrada por linfocitos y folículos linfoides y, además, puede estar estimulada por exceso de hormona tiroestimulante (TSH).

En Chile la carencia de yodo era una causa frecuente de bocio, problema que debería haber mejorado por lo menos en parte mediante la suplementación con yodo de la sal de mesa, de

1. Hospital Paula Jaraquemada, Instituto de Investigaciones Materno-Infantil (IDIMI), Facultad de Medicina, Universidad de Chile. acuerdo con la legislación que se estă aplicando desde $1978^{1,2}$. No obstante, el bocio continúa siendo frecuente en niños y adolescentes, por lo que deben plantearse otras etiologías. Estudios efectuados en otros países tienden a demostrar que la TLC sería causa importante de bocio en niños ${ }^{3-7}$

El diagnóstico de certeza de TLC se hace mediante biopsia tiroidea, pero por la naturaleza invasiva de este procedimiento se han buscado otros medios para orientar el diagnóstico. Fisher ha propuesto que la asociación de dos o más de los siguientes elementos sugiere la presencia de TLC $^{8}$ : bocio difuso de superficie finamente granular; cintigrafia algo irregular; anticuerpos antitiroideos por hemaglutinación positivos; concentración elevada de TSH en el suero o incremento inferior a $15 \%$ en la captación de yodo después de estimular con TSH y prueba positiva (20\%) de descarga con perclorato.

El presente trabajo es un estudio clínico y de laboratorio en pacientes con bocio, para describir la frecuencia con que se dan entre ellos los elementos clínicos y de laboratorio sugerentes de TLC, de acuerdo al criterio de Fisher, y deter. minadas diferencias con sujetos sin antecedentes personales y familiares de enfermedades endocrinas, en nuestro medio. 


\section{MATERIAL Y METODO}

Se estudiaron todos los pacientes que consultaron por prithera vez por bocio en nuestro Consultorio Externo de Endoctinología Infantíl del Hospital Paula Jaraquemada, entre los años 1983 y 1988, que fueron controlados por un período mínimo de un año: 58 mujeres y 2 hombres cuya edad fluctuaba entre 3 y 15 affos. No se incluyeron pacientes con tratamiento previo $\mathrm{ni}$ con bocio asociado con diabetes mellitus, aberración cromosómica, sindrome nefrótico, quistes, infiltraciones neoplísicas o no neoplásicas tiroideas. En todos los casos la anamnesis incluyó antecedentes familiares, lugar de procedencia, eventual ingestión de sustancias bociógenas y el examen físico, somatometría, características clínicas del bocio y signos de compromiso de la función tiroidea.

La función tiroidea se estudió mediante medición de concentraciones plasmáticas de hormonas tiroideas y TSH por ensayo radioinmune (RIA). Se consideraton valores normales para tiroxina (T4) 5,5 a $11,5 \%$ ig-di; triyodotiroxina (T3) 85 a $185 \mathrm{ng} \cdot \mathrm{dl}$; TSH 0,6 a 6,5 $\mu \mathrm{UI} \cdot \mathrm{ml}$. Se determinaron anticuerpos antitiroides, antimicrosomales $y$ antitiroglobulinas por hemaglutinación mediante el juego Sera Tek, Antes, cada 6 meses a un ä̃o. Se consideraron positivos los títulos desde $1 \times 100$.

Se solicitó cintigrafia tiroidea sólo en pacientes que presentaron consistencia tiroidea aumentada, asimetría ftanca, nódulo o ganglios cervicales, la que fue realizada en el Servicio de Medicina Nuclear del Hospital Salvador de Santiago.
Los pacientes fueron controlados por períodos de uno a cinco años. Fueron catalogados como TLC probable los pacientes que cumplían con 20 más de los siguientes requisitos: bocio difuso de superficie finamente irregular, de consistencia aumentada; anticuerpos antititoldeos positivos; TSH elevada o concentraciones anormales de hormonas tiroideas; cintigrafía con captación algo irregular. No se efectuó prueba de descarga de perclorato. Los pacientes con bocio sólo recibieron tratamiento cuando presentaban compromiso de la función tiroidea.

En 28 niños de edades similares, sin antecedentes personales de enfermedades endocrinas ni familiares de afecciones tiroideas, se realizaron tambjén determinaciones de anticuerpos microsomales y antitiroglobulinas, a manera de controles, mediante los procedimientos ya enunciados.

\section{RESULTADOS}

La distribución por edad de los 60 pacientes y 28 controles se describe en la tabla 1. Sólo había dos varones entre los pacientes con bocio. Se encontraron dos o mós criterios de TLC, de acuerdo con Fisher en 38/60 pacientes con bocio (probable TLC), cuya función tiroidea se expone en la tabla 2 .

Tabla 1

Distribución por edad de los pacientes con bocio y los controles

\begin{tabular}{lrrrr}
\hline $\begin{array}{l}\text { Edad } \\
\text { (años) }\end{array}$ & \multicolumn{2}{c}{ Pacientes con bocio $(\mathrm{n}-60)$} & \multicolumn{2}{c}{ Controles $(\mathrm{n}=28)$} \\
\hline 3 a 5 & $\mathrm{n}$ & $\%$ & $\mathrm{n}$ & $(7)$ \\
6 a 8 & 3 & $(5)$ & 2 & $(18)$ \\
9 a 11 & 14 & $(23)$ & 5 & $(25)$ \\
12 a 15 & 22 & $(37)$ & 7 & $(50)$ \\
\hline
\end{tabular}

Tabla 2

Caracter ísticas clínicas de los 38 pacientes con bocio y probable turoiditis linfocitaria crónica (TLC)

\begin{tabular}{|c|c|c|c|c|c|}
\hline $\begin{array}{l}\text { Edad } \\
\text { (años) }\end{array}$ & Hipertiroidismo & Eutiroidismo & Hipotitoidismo & Total & $\%$ \\
\hline 3 a 5 & 1 & - & - & 1 & $(2,5)$ \\
\hline 6 a 8 & 2 & 1 & 3 & 6 & $(15,0)$ \\
\hline $9 \times 11$ & 2 & 3 & 11 & 16 & $(42,0)$ \\
\hline 12 a 15 & 2 & 9 & 4 & 15 & $(40,5)$ \\
\hline Total n (\%) & $7(18,4)$ & $13(34,2)$ & $18(47,4)$ & 38 & $(100,0)$ \\
\hline
\end{tabular}


Tiroiditis e hipotiroidismo. 14 de ellos tenían hipotiroidismo desde su primera consulta, demostrado por $\mathrm{T} 4$ bajo (menor de $5,5 \mu \mathrm{g} \cdot \mathrm{dl}$ ) y TSH elevado (mayor de $6,5 \mu \mathrm{UI} \cdot \mathrm{ml}$ ); desde un punto de vista clínico, 9 de éstos presentaron síntomas de hipotiroidismo moderado, uno tenía hipotiroidismo florido, tres no tenian signos ni sintomas de hipotiroidismo y uno mostraba síntomas de hipertiroidismo; sin embargo, sus niveles de hormonas tiroideas eran bajos. En dos niños el hipotiroidismo apareció posteriormente, 1 y 3 años despues de reconocido el bocio, respectivamente. Todos estos pacientes fueron tratados con hormona tiroidea, no presentando mayores problemas, con excepción de la persistencia del bocio en algunos de ellos, a pesar de cumplir adecuadamente el tratamiento.

Tiroiditis y eutiroidismo. 13 pacientes con probable TLC permanecieron eutiroideos durante todo el período de observación. No se les indicó tratamiento.

Tiroiditis e hipertiroidismo, 7 de los pacientes con probable TLC tenian signos clínicos y de laboratorio de hipertiroidismo desde su primera consulta. El cuadro clínico de hipertiroidismo fue moderado y respondieron bien al tratamiento con propiltiouracilo.

En 22 pacientes no se encontraron elementos para considerarlo como probable TLC y fueron denominados "bocio no tiroiditis", 20 de ellos (914) tenían entre 6 y 15 años, casi todos eran eutiroideos, excepto uno con hipotìroidismo y otro con hipertiroidismo. En 2 niños con bocio eutiroideo había antecedentes de ingestión de medicamentos: uno habia recibido sulfas en forma prolongada, el otro un preparado conte. niendo yoduros (Paralymphine ${ }^{(B)}$ ), desapareciendo el bocio al suspender el medicamento.

En la tabla 3 se muestran los resultados de los anticuerpos microsomales realizados a los pacientes y a los controles. El valor mostrado en la tabla es el más alto entre todas las mediciones practicadas a cada paciente, las que fluctuaron entre 1 y 6 según el tiempo de observación. De los 38 pacientes con probable TLC, $12(31,5 \%)$ tenian ambos anticuerpos antimicrosomales $y$ antitiroglobulina ( $\mathrm{Tg}$ ) positivos en forma simultánea. Los títulos de $\mathrm{Ac} \mathrm{Tg}$ fluctuaron entre $1 \times 100$ y $1 \times 1.600$; ninguno de $\operatorname{los} 22$ pacien. tes con "bocio no tiroiditis" y de los 28 controles presentó Ac Tó positivos.

En proporción de $80 \%$, nuestros pacientes procedían de distintas comunas de Santiago; los restantes habitaban en otras regiones, sin predominio de ninguna en particular.

En $63 \%$ de los pacientes con probable TLC había otros miembros de la familia con bocio; en contraste, sólo 40\% de los nifíos con "bocio no tiroiditis" tenía e1 antecedente.

\section{COMENTARIO}

En nuestros pacientes estudiados con bocio se apreció un franco predominio del sexo femenino, a semejanza de lo descrito en Argentina ${ }^{4}$, pero diferente de la relación $2: 1$ encontrada

Tabla 3

Títulos de anticuerpos antimicrosomales en pacientes con bocjo y controles

\begin{tabular}{|c|c|c|c|c|c|c|}
\hline \multirow[t]{2}{*}{$\begin{array}{l}\text { Título de } \\
\text { anticuerpos }\end{array}$} & \multicolumn{2}{|c|}{$\begin{array}{l}\text { Pacientes con bocio y } \\
\text { probable TLC }(n=38)\end{array}$} & \multicolumn{2}{|c|}{$\begin{array}{l}\text { Pacientes con bocio } \\
\text { "no tiroiditis" }(n=22)\end{array}$} & \multicolumn{2}{|c|}{$\begin{array}{l}\text { Controles } \\
(n=28)\end{array}$} \\
\hline & $\mathbf{n}$ & $\%$ & $\mathbf{n}$ & $\%$ & $\mathbf{n}$ & $\%$ \\
\hline $1 \times 100$ & 6 & 16 & 2 & 9 & 1 & 3,5 \\
\hline $1 \times 400$ & 5 & 13 & 1 & 4,5 & 2 & 7 \\
\hline $1 \times 1.600$ & 11 & 29 & 0 & 0 & 0 & 0 \\
\hline $1 \times 6.400$ & 10 & 26 & 0 & 0 & 0 & 0 \\
\hline $1 \times 25.600$ o más & 6 & 16 & 0 & 0 & 0 & 0 \\
\hline Total & 38 & 100 & 3 & 13.5 & 3 & 10,5 \\
\hline
\end{tabular}

TLC = Tiroiditis linfocitaria crónica. 
por otros autores ${ }^{9}$. Las edades más frecuentes de presentación fueron las mayores de 9 años, concordando con otras publicaciones ${ }^{7,9}$ y la mayoria de los pacientes estudiados por bocio tenía dos o más elementos sugerentes de TLC según el criterio de Fisher.

En estos pacientes, con bocio y probable tiroiditis, es frecuente el compromiso de la función tiroider; de allí la importancia de plantear la posibilidad de tiroiditis en los pacientes con bocio, ya que en los "bocios no tiroiditis" es excepcional la alteración de la función glandular.

La elevada frecuencia de antecedentes familiares de afección lirsidea en pacientes con probable TLC puede orientar a una posible predisposición genética para afecciones de mecanismo autoinmune.

En la TLC se describe la formación de anticuerpos capaces de producir estimulación, supresión, fibrosis a destrucción del tiroides. Hay inmunidad alterada, tanto humoral como celular, sea por falla en la supresión de linfocitos $T$ antitiroideos o por liberación de antigenos secundaria a daño tiroideo por virus, traumatismos 0 inflamación, lo que iniciaría reacciones antígenoanticuerpo ${ }^{5,7,9}$.

En nuestros pacientes la detección de anticuerpos antimicrosomales (Ac M) y antitiroglo. bulina contribuyó de manesa importante en el diagnóstico de TLC (tabla 3); todos los casos de probable TLC presentaron Ac M positivos en algún momento de su evolución y casi un tercio tenían ambos anticuerpos positivos (AC M y Ac $\mathrm{Tg}$ ). En cambio, en la mayoría de los niños con "bocio no tiroiditis" ambos anticuerpos eran negativos. Por otra parte, en los pacientes con probabie TLC, los Ac M tienden a ser con mayor frecuencia positjos y en títulos más altos que para los Ac Tg. Los titulos tendieron también a ser más elevados y persistentes en la TLC.

La presencia de autoanticuerpos antimicrosomales o antitiroglobulina refleja la infiltración linfocitaria tiroidea. Sin embargo, la presencia de anticuerpos tiroideos positivos no es específica de TLC y títulos discretamente elevados pueden obseryarse en otras afeccjones. La cintigrafía parece justificada sólo en algunos pacientes en los que es indispensable hacer el diagnóstico diferencial con tumores, por la presencia de asimetría franca, ganglios, nódulos o aumento significativo de la consistencja de la glándula.

\section{RESUMEN}

Se estudiaron 60 pacientes con bocio, de 3 a 16 años de edad, 58 eran mujeres, 38 (63\%) de los cuales presentaba dos o más elementos sugerentes de tiroiditis linfocitaria crónica (TLC) (criterio de Fisher) destacando en ellos el compromiso de la función tiroidea $18 / 38(47,4 \%)$ con hipotiroidismo y $7 / 38(18,4 \%)$ con hipertiroídismo. Los demás pacientes con bocio difuso, que no cumplían los criterios de Fisher, fueron denominados "bocio no tiroiditis" (37\%) y eran eutiroideos en proporción de 95\%. En todos los pacientes con probable TLC se detectaron anticuerpos antimicrosomales en títulos relativamente altos. Sólo $32 \%$ tenían simultáneamente anticuerpos antimicrosomales y antitiroglobulinas positivos. Entre los 22 pacientes con "bocios no tiroiditis", 6 (28\%) tenían anticuerpos antimicrosomales positivos, en títulos bajos ( 1 × 100 y 1 × 400, respectivamente). En un grupo control de 28 niños de edades similares a los propósitos, sin enfermedades endocrinas ni antecedentes familiares de afecciones tirojdeas, sólo $3(11 \%)$ presentaron anticuerpos positivos, en títulos bajos.

(Palabras clave: bocio, tiroiditis linfocitaria crónica, hipotiroidismo, hipertiroidismo.)

\section{REFERENCIAS}

1. Muzzo S., Aguire $R$, Tellez A., Valoivieso $S$, Leiva L.: Bocio endémico en Pirque. Rev Chil Pediatr 1984; 55: 331-334.

2. Michaud P., Tellez R., Aguirre R, Tellez A. Voldivieso $S$.: Anticuerpos antitíroideos y prueba de yodo-perclorato de potasio en escolares con $y$ sin bocio endémico. Rev Med Chil 1983; 111: 1029-1032.

3. Mahoney C.: Differential diagnosis of goiter. Pediatr Clin North Am 1987; 34: 891-905.

4. Gruheiro L., Iorcansky S., Rivarola M., Bergadá C.: Variations in clinical hormonal and serological expressions of chronic lymphocytic thyroiditis in children and adolescents. Clin Endocrinol 1982; 16: $19-28$.

5. Reiter $O$., Root $A .$, Rettig $\boldsymbol{K}$., Vargas $A$. : Childhood thyromegaly: Recent developments. Pedia. trias 1981; 99: $507-518$

6. Hopwwod N., Rabin B., Foley T., Peake R.: Thyroid Antibodies in children and adolescents with thyroid disorders. J Pediatr 1978; 93: 57-61.

7. Bollison M., Dobyrs B., Keating T., Rale J., Tyler $F$.: Ocurrerce and natural history of chronic lymphocityc thyroiditis in childhood. J Pediatr 1975; 86: $675-682$ 